\title{
Steady-State Thermal-Hydraulic Analysis of the LEU-Fueled Dalat Nuclear Research Reactor
}

\author{
Kien-Cuong Nguyen (iD, Vinh-Vinh Le, Ton-Nghiem Huynh, Ba-Vien Luong, \\ and Nhi-Dien Nguyen $(\mathbb{D}$ \\ Dalat Nuclear Research Institute, Vinatom, 01 Nguyen Tu Luc Street, Dalat 670000, Lam Dong, Vietnam \\ Correspondence should be addressed to Nhi-Dien Nguyen; diennn.re@dnri.vn
}

Received 7 October 2020; Revised 2 February 2021; Accepted 14 February 2021; Published 28 February 2021

Academic Editor: Leon Cizelj

Copyright ( $\odot 2021$ Kien-Cuong Nguyen et al. This is an open access article distributed under the Creative Commons Attribution License, which permits unrestricted use, distribution, and reproduction in any medium, provided the original work is properly cited.

\begin{abstract}
This paper presents results of steady-state thermal-hydraulic analysis for the designed working core of the Dalat Nuclear Research Reactor (DNRR) using the PLTEMP/ANL code. The core was designed to be loaded with 92 low-enriched uranium (LEU) VVRM2 fuel bundles (FBs) and 12 beryllium rods surrounding a neutron trap at the core center, for replacement of the previous core with 104 high-enriched uranium (HEU) VVR-M2 FBs. Before using this code for thermohydraulic analysis of the designed LEU working core, it was validated by comparing calculation results with experimental data collected from the HEU working core of the DNRR. The discrepancy between calculated results and measured data was at the maximum about $0.8^{\circ} \mathrm{C}$ and $1.5^{\circ} \mathrm{C}$ of fuel cladding and outlet coolant temperatures, respectively. In the design calculation, thermohydraulic safety was confirmed through evaluation of the fuel cladding and coolant temperatures, as well as of other safety parameters such as Departure from Nucleate Boiling Ratio (DNBR) and Onset of Nucleate Boiling Ratio (ONBR). The calculation results showed that, in normal operation conditions at full nominal thermal power of $500 \mathrm{~kW}$ without uncertainty parameters, the maximum fuel cladding temperature of the hottest $\mathrm{FB}$ was about $90.4^{\circ} \mathrm{C}$, which is lower than its limit value of $103^{\circ} \mathrm{C}$, the minimum DNBR was 32.0 , which is much higher than the recommended value of 1.5, and the minimum ONBR was 1.43, which is higher than the recommended value of 1.4 for VVR-M2 LEU fuel type. When the global and local hot channel factors were taken into account, the maximum temperature of fuel cladding at the hottest FB was about $98.4^{\circ} \mathrm{C}$, for global only, and $114.3^{\circ} \mathrm{C}$, for global together with local hot channel factors. The calculation results confirm the safety operation of the designed LEU core loaded with 92 fresh VVR-M2 FBs.
\end{abstract}

\section{Introduction}

The DNRR is a 500-kW, pool-type research reactor that uses light water as a moderator and coolant. The reactor was modified and upgraded from an original 250-kW TRIGA Mark II reactor built in 1963. In November 1983, the initial core of the upgraded reactor was loaded with Russian VVRM2 HEU FBs of 36\% U-235 enrichment. The natural convection mechanism was reinforced by installing a $2 \mathrm{~m}$ high "chimney" above the reactor core, which permits the reactor to operate at a nominal thermal power of $500 \mathrm{~kW}$ [1]. The upgraded reactor retains some structures of the original TRIGA Mark II, including the graphite reflector, the horizontal beam tubes, the thermal column, and the biological shielding. From 2005 to 2012, the project on conversion of the DNRR core from HEU to LEU fuel was implemented. This was a two-phase project. In the first phase, the reactor core was partially converted in September 2007 to a mixed core of 98 irradiated HEU and 6 fresh LEU VVR-M2 FBs, and in the second phase, the reactor with an entire LEU core of $92 \mathrm{FBs}$ was commissioned and put into operation in early 2012. At present, the reactor is operated continuously for about $150 \mathrm{hrs}$ at full power, once every 1 or 2 weeks, for radioisotope production, neutron activation analysis, basic and applied researches, and education and training $[2,3]$.

For neutronics design calculation of the LEU working core, the MCNP-REBUS linkage system code was used to estimate the shutdown margin, the excess reactivity, the 
control rod's worth, the kinetics parameters, the burn-up distribution, and the power density distribution [4-6]. The power peaking factors with different positions of four shim rods inside the reactor core were also determined. The maximum power peaking factor was used for thermal hydraulic analysis in a conservative method. Because of the complicated geometry of the reactor and its FB, the DNRR was modelled by the MCNP5 code to meet the requirements of high fidelity of calculation results with 3 dimensions in space and of the continuous energy calculation library ENDF/B-VII.0 [7]. The PLTEMP/ANL code has been used for steady-state thermal-hydraulic analysis of the DNRR's LEU core with 92 FAs, because of its good correspondence to both the calculation model and numerical method [8]. After modification of the code, the calculation model of the DNRR with VVR-M2 fuel type, using the "chimney" and natural convection mode for heat removal, was satisfied.

Practically, the PLTEMP/ANL code was applied for steady-state thermal-hydraulic analysis for fuel conversion of research reactor cores using Russian tube fuel-types of VVR-KN and IRT-4M. A comparison of calculation results of the Kazakhstan WWR-K reactor core loaded with LEU VVR-KN fuel, using the PLTEMP/ANL and RELAP5 codes, was performed, and a good agreement was found between cladding surface temperatures calculated using PLTEMP/ ANL and those calculated using RELAP5-3D [9, 10]. The PLTEMP/ANL was also used for steady-state analysis of the Uzbekistan WWR-SM and IRT-Sofia reactors loaded with LEU IRT-4M $[11,12]$. Besides, the PLTEMP/ANL code was used to evaluate the safety parameters at a steady state of the hottest FB of the newly designed $10 \mathrm{MW}$ multipurpose research reactor using VVR-KN fuel [13]. In addition, the PLTEMP/ANL code was also applied for modeling and simulation of coupled nuclear heat energy deposition and transfer in the HEU pin-type fuel assembly, as well as for steady-state safety analysis of LEU core of the GHARR-1 reactor $[14,15]$. The verification and validation of the PLTEMP/ANL code were also carried out by comparison with experimental data and calculation results for thermohydraulic analysis of research reactors using MTR fuel [16].

In addition to thermohydraulic analysis of the designed 92 LEU VVR-M2 core for reactor core conversion and licencing its operation, the other purpose of this work was to validate the PLTEMP/ANL V3.8 code using the DNRR core loaded with 104 HEU VVR-M2 FBs. The obtained calculation results were compared with experimental data collected using a VVR-M2 instrumented fuel bundle (IFB) mounted with nine incorporated thermocouples on the fuel cladding [1]. This experimental method was also applied in validation of the code for steady-state thermal-hydraulic analysis of nuclear reactors with plate type fuels using experimental data from the IEA-R1 reactor in Brazil [17].

\section{VVR-M2 Fuel Types and Reactor Core Arrangement with LEU Fuel}

The standard VVR-M2 HEU and LEU fuel types $[1,18]$ have nearly the same characteristics in annulus geometry, with three coaxial tubes (fuel elements), including 2 cylindrical inner tubes and a hexagonally shaped outermost tube. Each fuel element is composed of a fuel meat, two aluminum cladding layers, and coolant channels on both sides of the fuel cladding. Both the HEU and LEU fuel types have the same thickness and total height of fuel element, and the same length of fuel meat. However, the thickness of the fuel meat and aluminum cladding differs between HEU and LEU fuel types. The U-235 mass and density of the LEU fuel are greater than those of HEU fuel. Detailed parameters of HEU and LEU VVR-M2 fuel types are described in Table 1 and illustrated in Figure 1.

The working core was loaded with 92 LEU FBs and 12 beryllium rods located around the neutron trap. The beryllium rods arrangement in the core center region can be avoided to get a high power density of FBs to be loaded near the neutron trap. In addition, the beryllium layers contribute to the thermalizing process of the neutron, creating high thermal neutron flux at the neutron trap that approximates the previous HEU core or mixed HEU and LEU core, with maximum thermal neutron flux of $2.2 \times 10^{13} \mathrm{n} \mathrm{cm}^{-2} \cdot \mathrm{s}^{-1}$.

The reactor core is immersed in demineralized water in the reactor tank of diameter $2 \mathrm{~m}$ and height $6.2 \mathrm{~m}$. The extracting well (chimney) of length $2 \mathrm{~m}$ is located at the top of the reactor core. The main characteristics and detailed geometry of the DNRR are shown in Table 1 and depicted in Figures 2 and 3(a), respectively. Compared with the HEU core and the mixed core of HEU and LEU, the new LEU core has a larger total U-235 loaded mass. Consequently, the operation time can be longer.

The two dry irradiation channels at cells 7-1 and 13-2 are mainly exploited for neutron activation analysis of short-lived isotopes. The wet channel at cell 1-4, the rotary specimen with 40 irradiation holes, and the neutron trap are used mainly for production of ${ }^{131} \mathrm{I}$ and ${ }^{32} \mathrm{P}$ radioisotopes. Four horizontal beam tubes, including 1 tangential and 3 radial beam tubes, are used for nuclear data measurement and neutron basic research based on silicon and bismuth filtering techniques for creating mono-energy neutrons [2].

To control the reactor, 2 safety rods and 4 shim rods made of boron carbide $\left(\mathrm{B}_{4} \mathrm{C}\right)$ and an automatic regulating rod made of stainless steel are used; these rods are symmetrically arranged inside the reactor core. During the reactor operation, two safety rods are fully withdrawn and ready to drop freely into the core by natural gravity.

The instrumented fuel bundle (IFB) mounted with nine chrome-copper thermocouples was used to measure the temperatures of the fuel cladding surfaces and the inlet and outlet coolants of the reactor core. The IFB is a HEU VVRM2 fuel type with $40.2 \mathrm{~g}$ of U-235 and considered as fresh fuel because of its limited irradiation time inside the reactor core, which is suitable for short-time experiments only. The 5 thermocouples from $T_{1}$ to $T_{5}$ are located in the aluminum cladding of the hexagonal outer tube, $\mathrm{T}_{6}$ and $\mathrm{T}_{7}$ are incorporated in the aluminum cladding of the two cylindrical inner tubes, and $\mathrm{T}_{8}$ and $\mathrm{T}_{9}$ are in direct contact with the coolant to measure the inlet and outlet coolant temperatures. A detailed illustration of the IFB is shown in Figure 3(b). 
TABLE 1: Characteristics of the DNRR and its HEU and LEU VVR-M2 fuel types.

\begin{tabular}{|c|c|c|}
\hline \multirow{2}{*}{ Parameter } & \multicolumn{2}{|c|}{ Value } \\
\hline & HEU fuel used (3/1984-5/2011) & LEU fuel used (11/2011-present) \\
\hline \multicolumn{3}{|l|}{ Open-pool type reactor: } \\
\hline Nominal thermal power (MW) & \multicolumn{2}{|c|}{0.5} \\
\hline Moderator and coolant & \multicolumn{2}{|c|}{ Light water } \\
\hline Reflector material & \multicolumn{2}{|c|}{ Graphite, beryllium, and water } \\
\hline Convection mechanism & \multicolumn{2}{|c|}{ Natural } \\
\hline Active core height & \multicolumn{2}{|c|}{$60 \mathrm{~cm}$} \\
\hline Core equivalent diameter & \multicolumn{2}{|c|}{$44.2 \mathrm{~cm}$} \\
\hline Number of fuel elements in fuel bundle: & \multicolumn{2}{|c|}{3} \\
\hline Hexagonal shape (outermost) & \multicolumn{2}{|c|}{1} \\
\hline Cylindrical shape (two inner) & \multicolumn{2}{|c|}{2} \\
\hline Fuel pitch of fuel bundle ( $\mathrm{mm})$ & \multicolumn{2}{|c|}{35} \\
\hline \multicolumn{3}{|l|}{ Fuel thickness $(\mathrm{mm})$ : } \\
\hline Fuel element (fuel cladding and fuel meat) & \multicolumn{2}{|c|}{2.5} \\
\hline Fuel meat & 0.7 & 0.94 \\
\hline Fuel cladding (SAV1) & 0.9 & 0.78 \\
\hline Coolant gap & \multicolumn{2}{|c|}{$2.5-3.0$} \\
\hline Uranium density of fuel meat (\%) & 1.40 & 2.50 \\
\hline Fuel meat composition & U-Al alloy & $\mathrm{UO} 2+\mathrm{Al}$ \\
\hline \multicolumn{3}{|l|}{ Fuel height (mm): } \\
\hline Total & \multicolumn{2}{|c|}{865} \\
\hline Fuel element & \multicolumn{2}{|c|}{700} \\
\hline Fuel meat & \multicolumn{2}{|c|}{600} \\
\hline \multicolumn{3}{|l|}{ U-235 in fuel bundle: } \\
\hline Enrichment (\%) & 36 & 19.75 \\
\hline Mass (g) & 40.2 & 50 \\
\hline
\end{tabular}

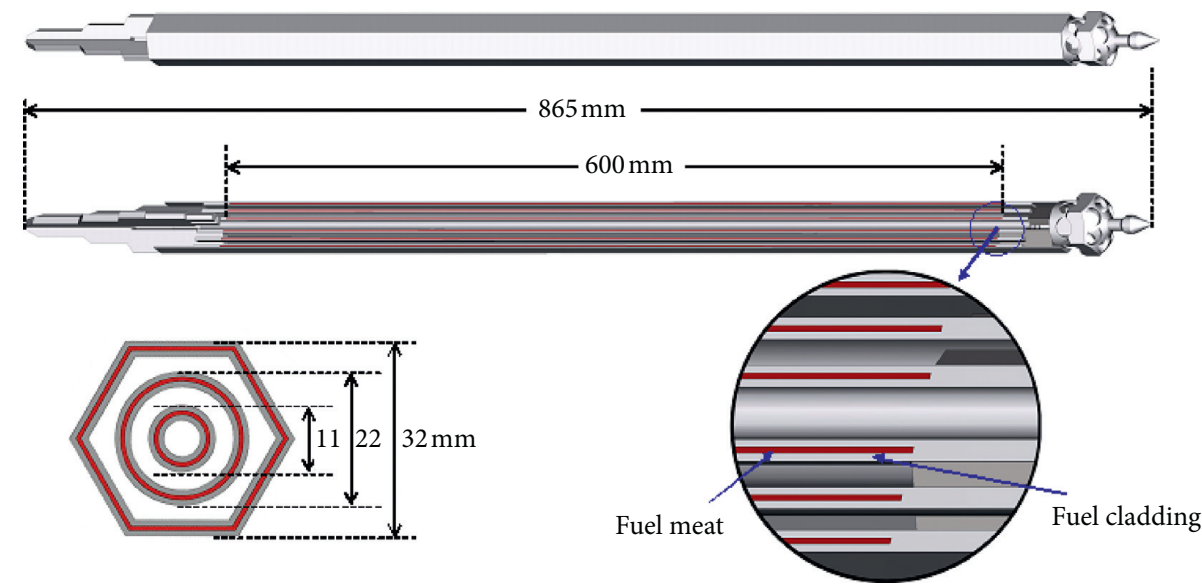

Figure 1: VVR-M2 fuel bundle parameters.

\section{Calculation Method}

3.1. PLTEMP/ANL Code. The PLTEMP code was originally developed by Mishima [19] for thermal hydraulic analysis of the Kyoto University Research Reactor loaded with curved plate MTR FBs and operated at a thermal power level of $5 \mathrm{MW}$. The code was then improved and extended to cover thermal hydraulic analysis for research reactors that use Russian concentric tube-type FBs, such as IRT-4M, VVR$\mathrm{KN}$, and VVR-M2, at the Argonne National Laboratory,
USA. The code has the ability to solve the problem of hottest single FB or few FBs, as well as of whole core calculation. The PLTEMP/ANL3.8 code was improved by adding some new features for thermal hydraulic analysis of research reactors at steady-state condition, in which one important feature was a revision of the coolant property library tables that were made identical to those used by the PARET/ANL code [20]. Many heat transfer correlations were also added for use if the relevant problems arise. The six hot channel factors used in these versions are also applicable to natural convection. In 


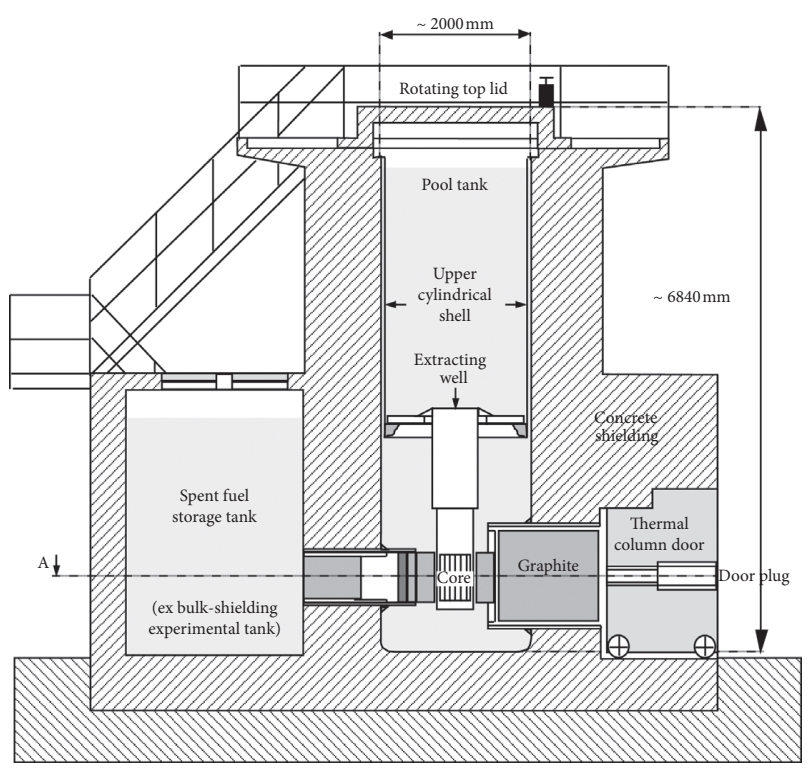

(a)

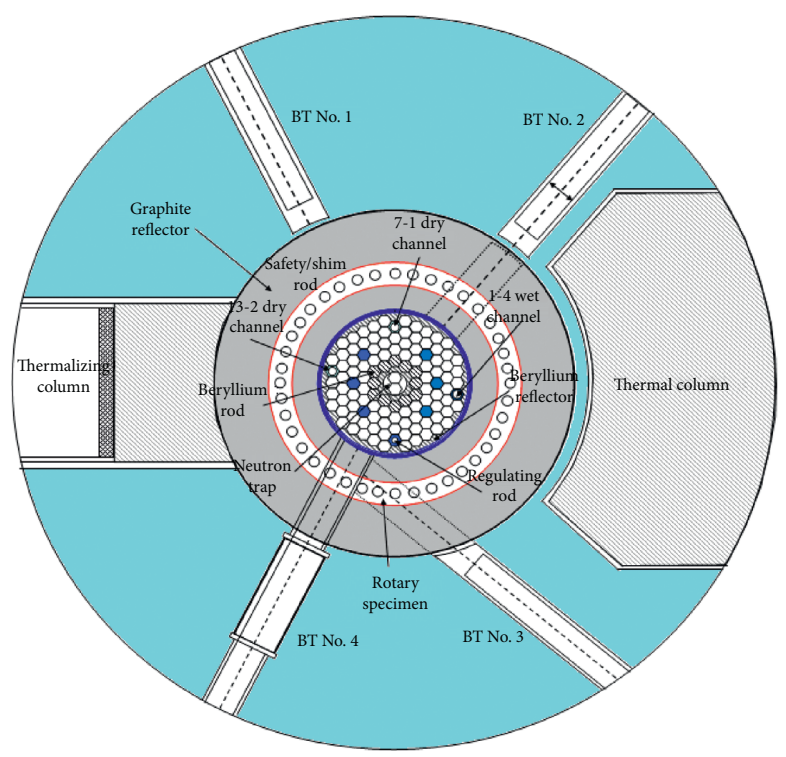

(b)

FIgURE 2: Vertical (a) and horizontal (b) cross section of the LEU-fueled DNRR.

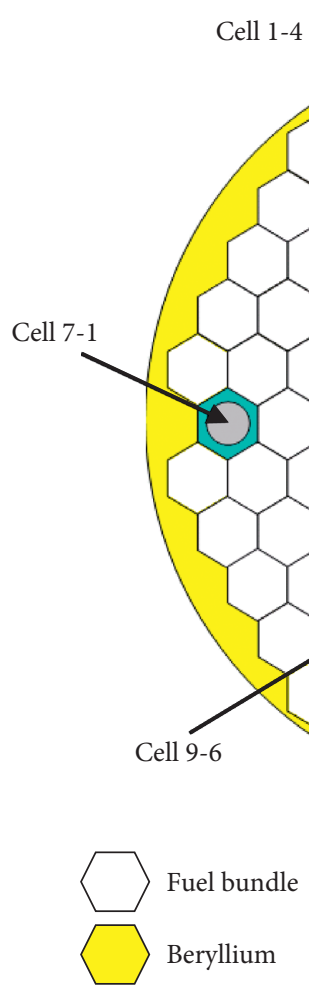

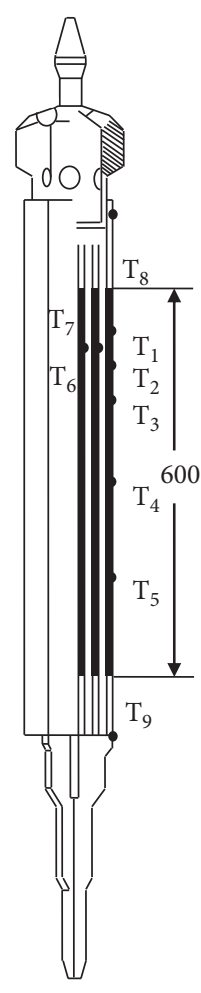

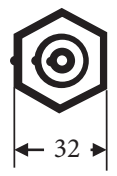

(b) (a)

Dry and wet channels

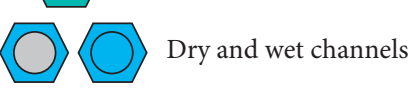

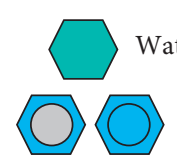

Cell 13-2

IGURE 3: The reactor core configuration with 104 HEU VVR-M2 FBs (a) and IFB (b).

general, the code has three main solutions for temperature profiles, which include the Broyden method [21] and the analytical method for 3-layer plates (fuel meat and claddings), and the analytical method for 5-layer plates (fuel meat, gas gaps, and claddings).
The PLTEMP/ANL3.8, with a "chimney" or extracting well model and Collier's heat transfer correlation [22], is quite adequate for the DNRR, which operates at low pressure and uses natural convection for heat removal. The laminar, turbulent, and transient modes of mixed 
convection are included in the code as equations $(1) \div(3)$, respectively:

$$
\begin{aligned}
& N u_{L}=\left\{\max \left[\mathrm{CL} 1, \mathrm{CL} 2 * \operatorname{Re}_{b}^{\mathrm{CL} 3} \operatorname{Pr}_{b}^{\mathrm{CL} 4}\left(\frac{\operatorname{Pr}_{b}}{\operatorname{Pr}_{W}}\right)^{\mathrm{CL} 5}\left(\frac{g \beta \rho^{2} D_{e}^{3}\left(T_{w}-T_{b}\right)^{\mathrm{CL} 6}}{\mu^{2}}\right)\right]\right\}, \quad \text { if } \operatorname{Re}<\mathrm{RE} 1, \\
& N u_{T}= 0.023 R_{b}^{0.8} \operatorname{Pr}_{b}^{0.4}, \quad \text { if } \mathrm{Re} \geq \mathrm{RE} 2, \\
& N u_{L}+\frac{(\operatorname{Re}-\mathrm{RE} 1)}{\mathrm{RE} 2-\mathrm{RE} 1}\left(N u_{T}-N u_{L}\right), \quad \text { if RE} 1 \leq \mathrm{Re} \leq \mathrm{RE} 2,
\end{aligned}
$$

where the recommended values are as follows: $\mathrm{CL} 1=4.0$, $\mathrm{CL} 2=0.17, \mathrm{CL} 3=0.33, \mathrm{CL} 4=0.43, \quad \mathrm{CL} 5=0.25, \quad \mathrm{CL} 6=0.1$, $\mathrm{RE} 1=2000$, and RE2 $=2500$. The subscript $b$ refers to the bulk coolant and $w$ refers to the coolant at the wall temperature. Re is the Reynolds number $\left(\rho V D_{e} / \mu\right)$, Pr is the Prandtl number $\left(\mu C_{p}\right)$ $k), \mu_{b}$ is the $\sum_{\mathrm{f}}$ dynamics viscosity of the bulk liquid coolant $(\mathrm{kg} /$ (m.s)), $\mu_{w}$ is the dynamics viscosity of the coolant at the wall temperature $(\mathrm{kg} /(\mathrm{m} . \mathrm{s})), k_{\mathrm{b}}$ is the bulk coolant conductivity, $D_{\mathrm{e}}$ is the hydraulic diameter $(\mathrm{m}), \beta$ is the gap of the rectangular channel or annulus (m), $\mathrm{s}$ is the span of the channel (m), and $g$ is the acceleration due to gravity $\left(9.80665 \mathrm{~m} / \mathrm{s}^{2}\right)$.

Shah's CHF correlation [23] was implemented to make the code suitable for the DNRR thermal hydraulic calculation and analysis. The Forster-Greif correlation was used to determine the ONBR in the case of the hot channel factors for safety analysis as

$$
\begin{aligned}
\Delta T_{\text {sat }} & =\frac{0.182 q^{0.35}}{P^{0.23}}, \\
T_{w} & =T_{\text {sat }}+\Delta T_{\text {sat }},
\end{aligned}
$$

where $q$ is the heat flux in $W / \mathrm{m}^{2}, P$ is the pressure of the coolant in bar, and Tor $\Delta T$ ( $w$ : water and sat: saturation) is the temperature in ${ }^{\circ} \mathrm{C}$.

In the PLTEMP/ANL3.8 version, the hot channel factors can be applied in thermal hydraulic analysis to estimate safety margin parameters such as the ONBR, DNBR, and flow instability ratio (FIR) [24]. When using the hot channel factors, three steps of calculation are carried out. The first step is done as a normal calculation. The second step is a repetition of the first step with an increase in the reactor power and a decrease in the reactor flow to determine uncertainty in the Nusselt number correlation. The last step applies the hot channel factors to the bulk coolant, film temperature, and cladding surface heat fluxes obtained in the previous step. The hot channel factors of the code have two parts: global and local. In the global hot channel factors, the reactor power, flow rate, and heat transfer coefficient (correlation of the Nusselt number) are presented, while the local hot factors include bulk coolant temperature rise, local coolant film temperature rise, and heat flux from the cladding surface. The combined random uncertainties and the combined systematic errors are used to estimate the local and global hot channel factors, respectively.
In each node at an axial direction of the hottest or average channel, the output of the code includes the temperature, the ONBR, and the temperature of water saturation and the ONB temperature condition of the fuel cladding. Other safety parameters, including the ONBR, DNBR, and FIR, are also calculated and shown in the output file.

3.2. Modeling. The LEU VVR-M2 fuel bundle has three coaxial annular tubes (fuel elements). The outermost fuel element has a hexagonal shape and is of $32 \mathrm{~mm}$, with the $35 \mathrm{~mm}$ being of FB pitch in width across parallel sides. The other two inner fuel elements have circular shapes of outer diameters $22 \mathrm{~mm}$ and $11 \mathrm{~mm}$, respectively (see Figure 1). The thickness of the fuel meat of the $\mathrm{UO}_{2}-\mathrm{Al}$ dispersion is $0.94 \mathrm{~mm}$ and that of the aluminum clad is $0.78 \mathrm{~mm}$ on each side. There exists a gap of about $2.5-3 \mathrm{~mm}$ between adjacent fuel elements for coolant flow. In the PLTEMP code, the VVR-M2 fuel was modelled with three coaxial cylinders as detailed in Figure 4(b). In the calculation model, the outermost cylinder preserves the conversion area of the original hexagonal tube. The working core of 92 LEU FBs was modelled with 2 hot channels (at cell 10-5 and cell 4-5 in Figure 4(d)) and 90 average channels, with a $2 \mathrm{~m}$ height "chimney" also taken into account. At the design calculation stage, the channel in cell 13-2 in Figure 4(d) was considered as a full-water channel. The 12 beryllium rods were arranged in such a way as to avoid high power density of the FBs located near the neutron trap and to increase neutron thermalization for radioisotope production.

3.3. Code Validation. Before the PLTEMP/ANL3.8 code was used for thermal hydraulic analysis of the DNRR loaded fully with LEU FBs, it was validated by comparing the analytical results with the experimental data of the working core loaded with $104 \mathrm{HEU}$ FBs at the full power of $500 \mathrm{~kW}$. The power peaking factors of the IFB for the PLTEMP code input were calculated by the MCNP5 code. The hottest FB was determined at cell 9-6 (see Figure 3). The IFB was then put in this position to measure temperatures using seven thermocouples, five of which $\left(\mathrm{T}_{1} \div \mathrm{T}_{5}\right)$ were used to measure the cladding surface temperature of the outermost tube and the two others $\left(T_{8}\right.$ and $\left.T_{9}\right)$ to measure the coolant temperature at the entrance and exit of the flow channel, respectively. The error of this measurement system is about $\pm 3^{\circ} \mathrm{C}$. The 

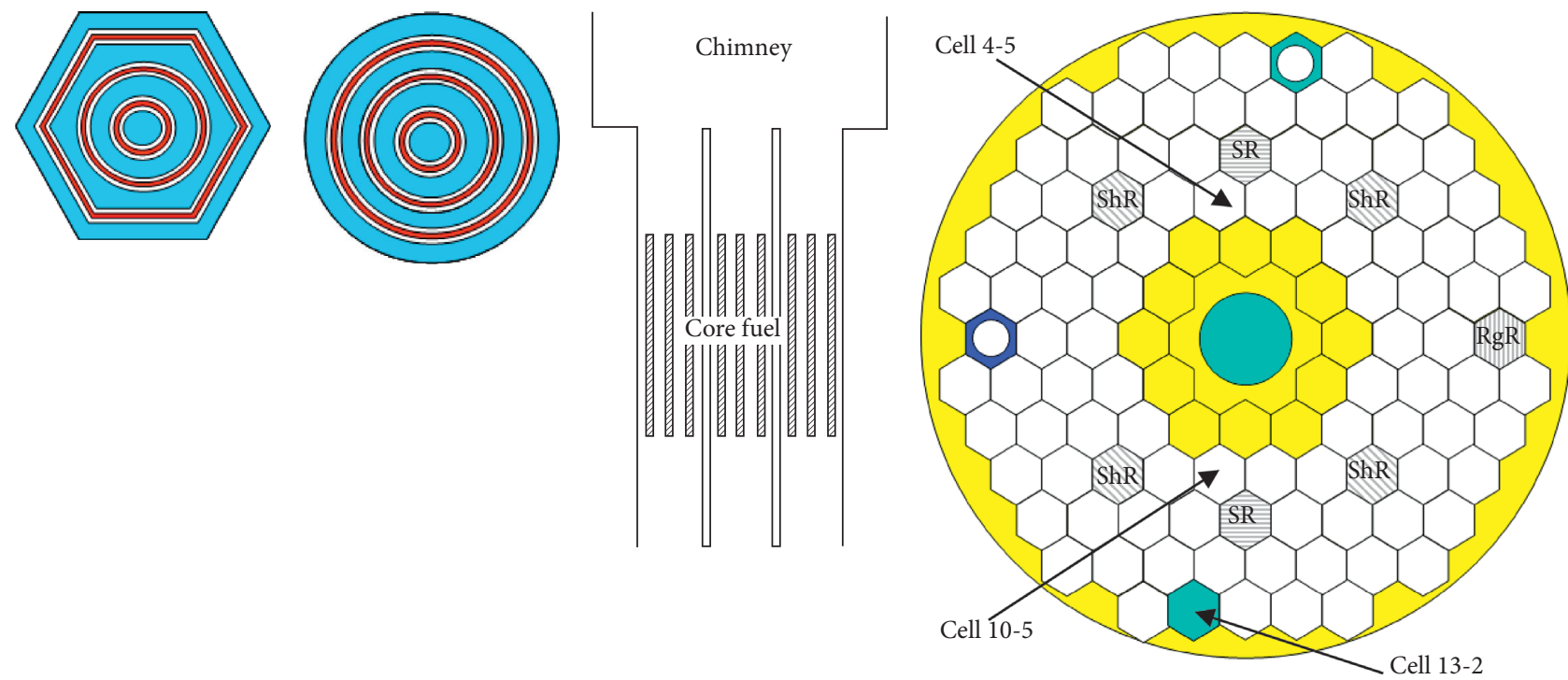

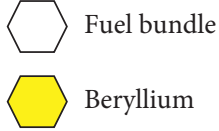

(c)

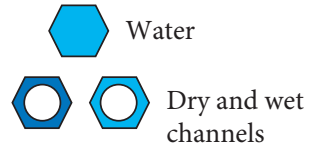

(d)

Figure 4: The DNRR model calculation for the PLTEMP/ANL code and LEU core with 92 FBs. (a) Fuel bundle cross-section. (b) Fuel bundle cross-section model. (c) Reactor coolant system model for PLTEMP/ANL code. (d) LEU working core with 92 FBs.

comparative results of the calculated and measured data in Figure 5 show that the discrepancy between calculated results and experimental data is not significant. Except for the difference of about $1.5^{\circ} \mathrm{C}$ at the outlet coolant channel, the difference in other temperatures was below $1^{\circ} \mathrm{C}$ and fully addressed by the error of the measurement system. A good agreement between calculation results and measurement data for DNRR's HEU core allows the PLTEMP/ANL3.8 code to be used "adequately" for its LEU core due to the very similar geometry, power level, and coolant flow rate.

3.4. Power Density Distribution of the LEU Core. The MCNP5 code was used to calculate power distribution with 30 nodes in the axial direction of the hottest FB at cell 10-5 (see Figure 4(d)). The average power distribution in the radial direction of each FB was estimated, together with local power peaking of each cylindrical and hexagonal tube. Figure 6 shows the axial relative power distributions (axial power peaking factors) of the hottest FB by different insertions of the shim rods. The calculated results show that the maximum axial power peaking factor was 1.37 , corresponding to the $25 \mathrm{~cm}$ insertion of 4 shim rods. The radial power peaking factors were 1.41 and 1.38 for the reactor core and the FB in the local hot channel, respectively. The most powerful FB was found to be next to a beryllium layer around the neutron trap (cell 4-5 and cell $10-5$ in Figure 4(d)). The details of the power peaking factor of the hottest FB, according the control rod positions, were also obtained. Two of the six sides of the hottest FB conduct no heat, because this FB is located near the beryllium rod around the neutron trap.

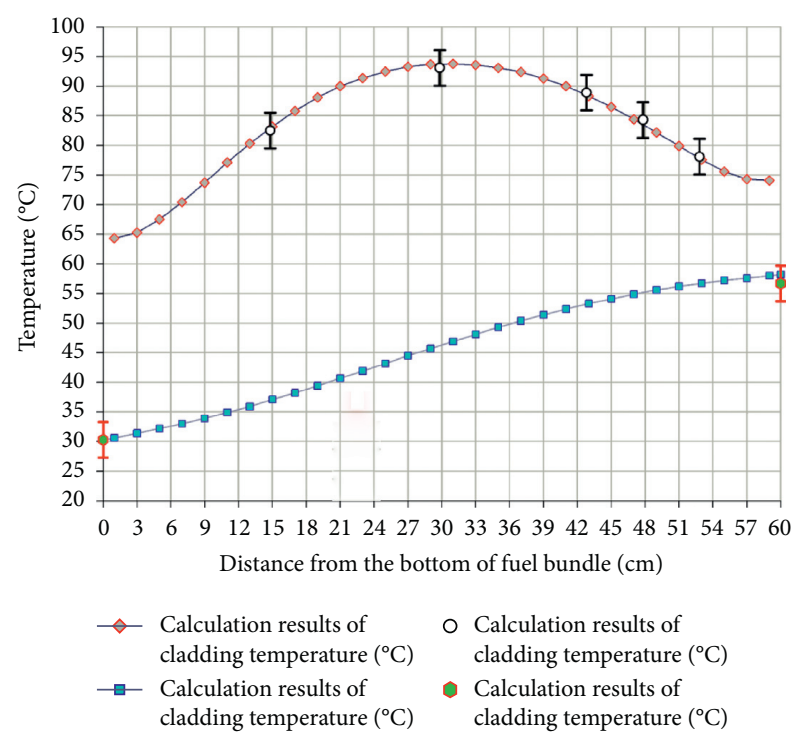

Figure 5: Comparison of the measured cladding temperatures $\left(\mathrm{T}_{1} \div \mathrm{T}_{5}\right)$ and coolant temperatures $\left(\mathrm{T}_{\mathrm{in}}, \mathrm{T}_{\text {out }}\right)$ of the HEU core to calculated those of the LEU core using the PLTEMP/ANL code.

3.5. Hot Channel Factors of the LEU Core. There are six hot channel factors of the PLTEMP code: the reactor power, the coolant flow, and the Nusselt number correlation in the global part and the bulk coolant temperature, the coolant film temperature, and the heat flux from the cladding surface in the local part. These factors are used to calculate the ONBR, the DNBR, and the maximum fuel cladding and 


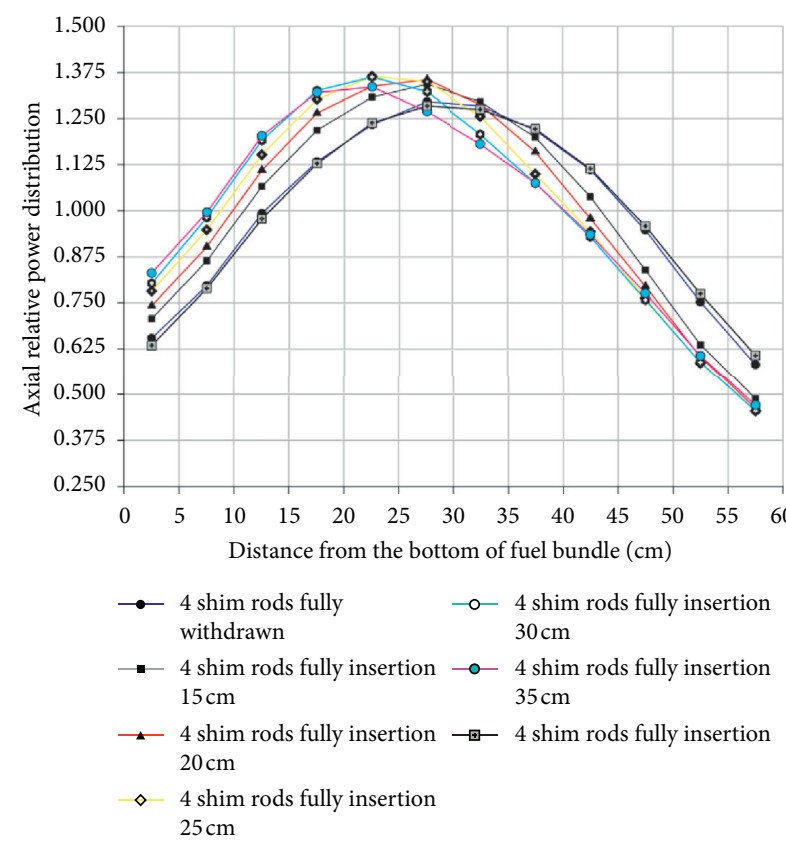

(a)

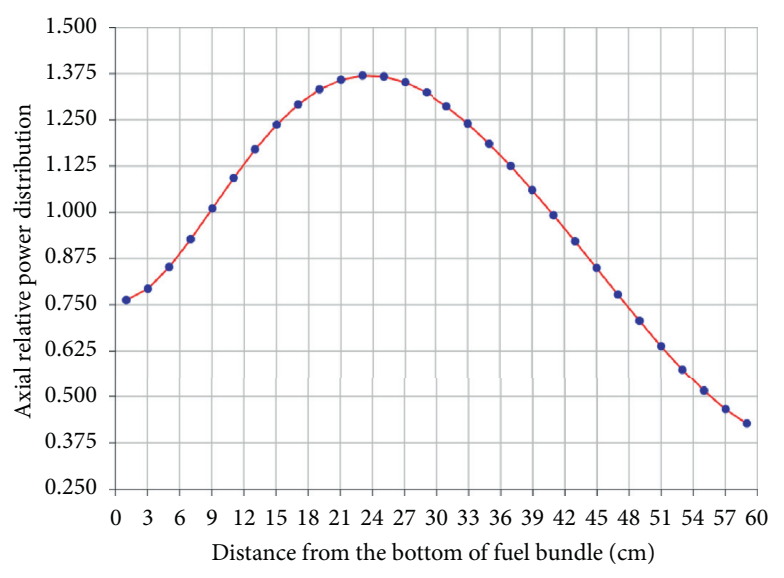

(b)

Figure 6: Axial relative power distributions (power peaking factors) of the hottest FB (at cell 10-5) calculated by the MCNP5 code for different insertions (a) and for $25 \mathrm{~cm}$ insertion of 4 shim rods (b).

coolant temperatures. The separate calculation of the three global factors is available. Table 2 presents the hot channel factors of the DNRR LEU core prepared for the PLTEMP/ ANL code according to the method proposed by Feldman [24]. The first three factors were statistically combined from the random uncertainties of the fuel meat thickness, the U-235 homogeneity, the U-235 mass per fuel element, the power density, the cooling channel spacing, and the flow distribution, as given by the VVR-M2 fuel catalogue [18]. This statistical combination was used for the random uncertainties because it was unlikely that all of these sources could adversely affect the limiting value of the core simultaneously. Three other factors are the systematic uncertainties of the reactor power measurement, coolant flow measurement, and heat transfer coefficient, which affect all regions of the reactor core equally. The combined factor of the random uncertainties [24] can be calculated according to

$$
F=1+\sqrt{\sum_{i}\left(1-F_{i}\right)^{2}}
$$

and the statistic combination errors [24] can be determined by multiplying all factors with $F_{i}$ by

$$
F=\prod_{i} F_{i} .
$$

\section{Results and Discussion}

Steady-state thermal-hydraulic calculation for the DNRR loaded with LEU fuel was implemented by the PLTEMP/ ANL in three steps. At the beginning, a normal calculation
TABLE 2: Hot channel factors in thermal hydraulic analysis of the DNRR.

\begin{tabular}{lc}
\hline Hot channel factors & Value \\
\hline Uncertainty in heat flux & 1.17 \\
Uncertainty in bulk coolant temperature rise & 1.34 \\
Uncertainty in film temperature rise & 1.21 \\
Uncertainty in power measurement & 1.05 \\
Uncertainty in flow measurement & 1.02 \\
Uncertainty in heat transfer coefficient & 1.15 \\
\hline
\end{tabular}

without hot channel factors at power levels of $500 \mathrm{~kW}$, $550 \mathrm{~kW}$, and $600 \mathrm{~kW}$ together with the inlet coolant temperature of $32^{\circ} \mathrm{C}$ was carried out. Then, the calculation was performed with global hot channel factors, and the last calculation was carried out by using all global and local hot channel factors.

4.1. Without Hot Channel Factors. The best-estimate calculation results of the DNRR are shown in Figure 7. The maximum cladding surface temperature was determined to be $90.4^{\circ} \mathrm{C}$, which was far below the estimated ONB temperature of $115.8^{\circ} \mathrm{C}$ using the Forster-Greif correlation. It met the requirement that the maximum fuel cladding temperature must be lower than $103^{\circ} \mathrm{C}$ at the nominal power as recommended by the fuel supplier [18]. Using the maximum permissible inlet temperature of $32{ }^{\circ} \mathrm{C}$, the maximum coolant temperature at the core exit was calculated to be $57.7^{\circ} \mathrm{C}$. This value was very low compared to the saturation temperature of $108^{\circ} \mathrm{C}$. For a thin layer of the fuel element tube, the temperature of the fuel meat was only 


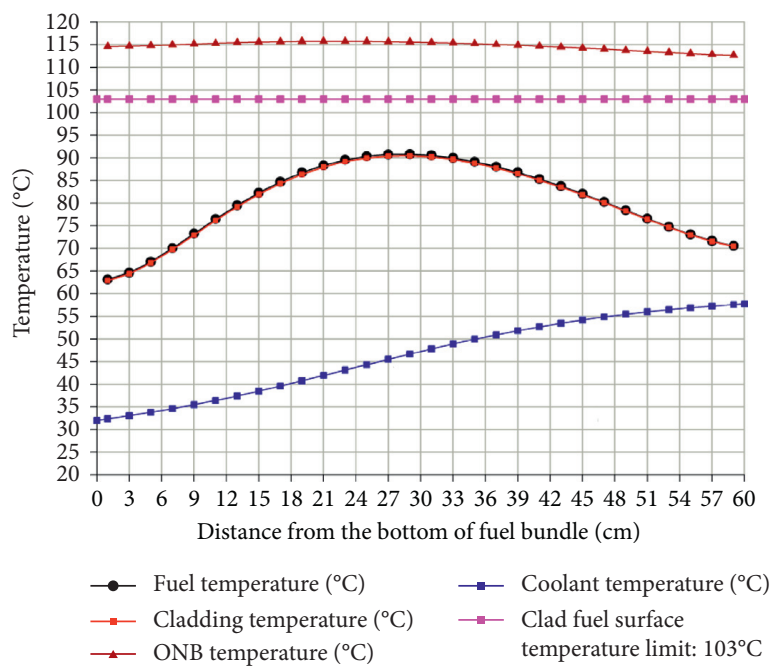

Figure 7: Calculated temperatures at nominal power without hot channel factors in the hottest FB.

slightly higher than that of the cladding, with the maximum difference only $0.4^{\circ} \mathrm{C}$. The calculated results showed that the minimum DNBR was 32.0, the minimum ONBR was 1.43 , and the total coolant flow rate through the reactor core was about $26.3 \mathrm{~m}^{3} / \mathrm{h}$. The calculation results were in good confirmation for the safe operation of the DNRR when using LEU fuel.

If the reactor power increased up to $550 \mathrm{~kW}$ and $600 \mathrm{~kW}$, we can see from the calculation results that the maximum fuel cladding surface temperature would rise to 94.2 and $97.7^{\circ} \mathrm{C}$, corresponding with the maximum coolant temperature of 59.2 and $60.0^{\circ} \mathrm{C}$, respectively. Figure 8 shows the calculation results of the fuel cladding and coolant temperatures at different reactor power levels.

The maximum fuel cladding surface temperature at the thermal power of $600 \mathrm{~kW}$ was still below its limitation temperature of $103^{\circ} \mathrm{C}$. In practice, however, the maximum operational power is about $550 \mathrm{~kW}$, corresponding to $110 \%$ of the nominal reactor power, so the fuel cladding temperature still remained less than $95^{\circ} \mathrm{C}$. According to the recorded technological operation data in the operating logbook, the uncertainty in the power is only $5 \%$, which meets the requirement of the maximum fuel cladding temperature of less than $103^{\circ} \mathrm{C}$.

4.2. With Global Hot Channel Factors. Taking into account the systematic uncertainties in the global hot channel factors increased, the maximum cladding surface temperature became $98.4^{\circ} \mathrm{C}$, which was well below the maximum fuel cladding temperature of $103^{\circ} \mathrm{C}$ and far below the estimated ONB temperature of $115.9^{\circ} \mathrm{C}$ as shown in Figure 9. All global hot channel factors of the DNRR can be determined through experiments or operational data. Based on the flow rate of the primary and secondary cooling systems and light water properties, the thermal power of the reactor was estimated and recorded during normal operation for each hour. The total data were analyzed to validate the PLTEMP/ANL thermal-hydraulic analysis code. When the DNBR value was

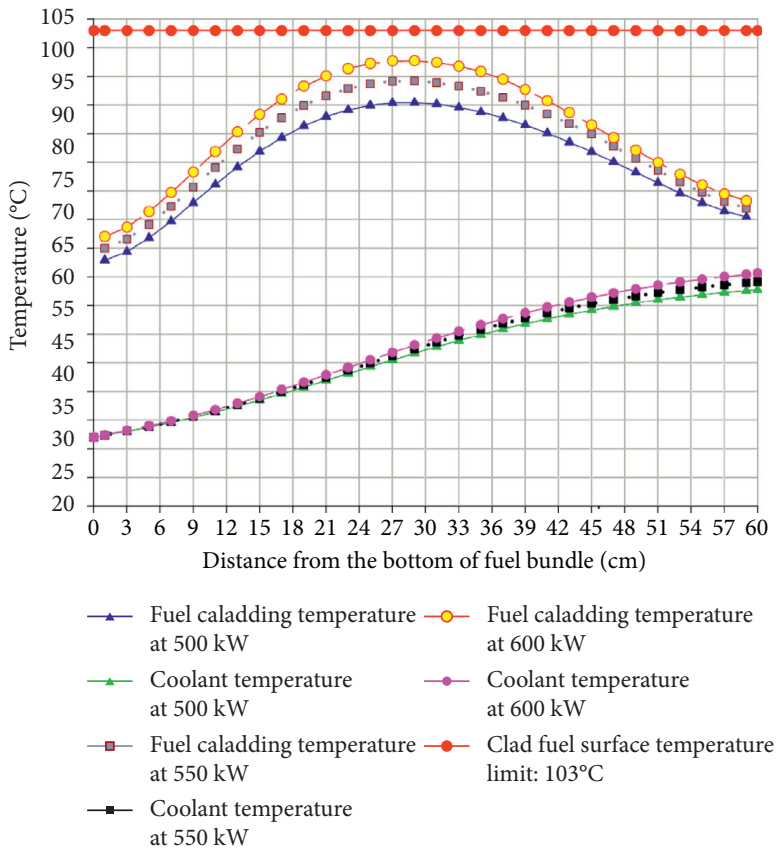

Figure 8: Comparison of the fuel cladding and coolant temperatures at different reactor power levels.

17.79 , the ONBR value was 1.26 , the total coolant flow rate through the reactor core was $26.3 \mathrm{~m}^{3} / \mathrm{h}$, and the coolant temperature of $58.8^{\circ} \mathrm{C}$ at the outlet of the hottest $\mathrm{FB}$ was still extremely low compared with the saturation temperature of $107^{\circ} \mathrm{C}$. Yet, the DNRR still met thermal-hydraulic safety at the steady-state condition.

4.3. With all Global and Local Hot Channel Factors. Calculation results for nominal power with all systematic and random uncertainties taken into account are shown in Figure 10. In this calculation step, hot channel factors were applied to the bulk coolant, local coolant film temperature rises, and the cladding surface heat fluxes were obtained in 


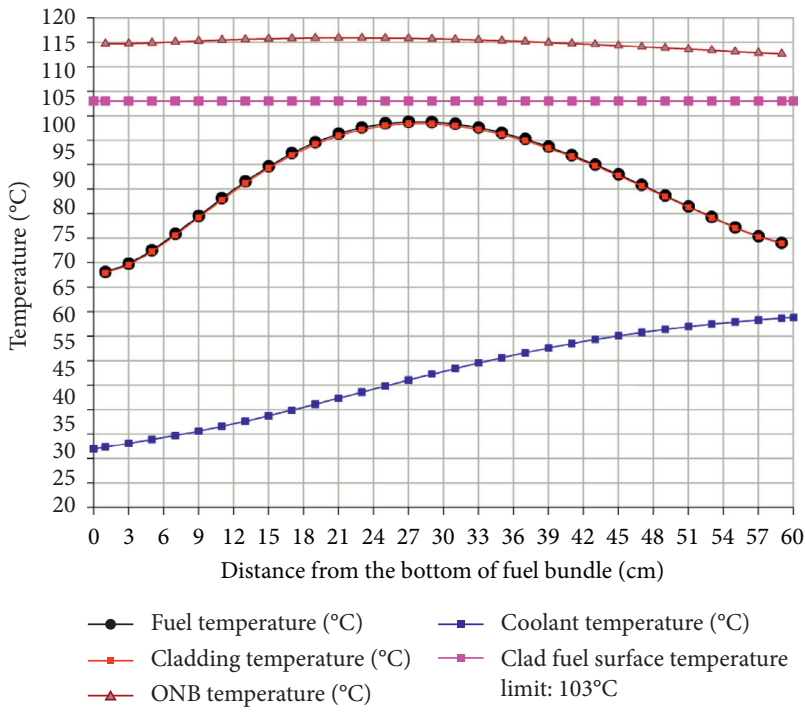

FIgURE 9: Calculated temperatures at nominal power with global hot channel factors (with systematic uncertainties).

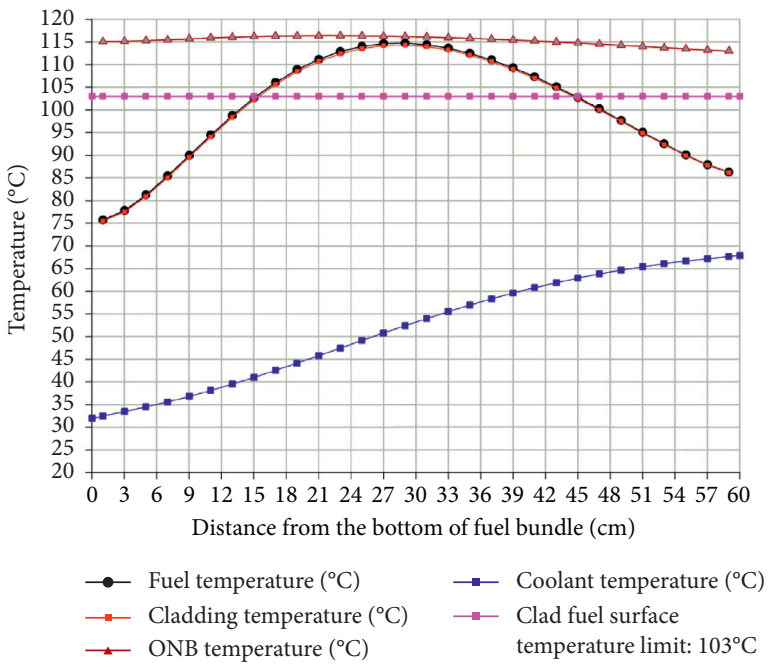

FIGURE 10: Calculated temperatures at nominal power with global and local hot channel factors (with systematic and random uncertainties).

the previous step. The maximum fuel cladding temperature was $114.3^{\circ} \mathrm{C}$, which was only a few degrees less than the predicted ONB temperature of $116.4^{\circ} \mathrm{C}$. Using Shah's correlation, the obtained minimum DNBR value of 15.2 was far above the limit value of 1.5 specified for the VVR-M2 LEU fuel of the DNRR $[1,18]$. The maximum coolant temperature with all global and local hot channel factors considered was about $68^{\circ} \mathrm{C}$, which was lower than the saturation value of $107^{\circ} \mathrm{C}$. The ONBR value in this case was only 1.02 and obtained nearly to the boiling point. However, the integrity of the fuel cladding was still confirmed because the melting point of the aluminum material is about $650^{\circ} \mathrm{C}$.

\section{Conclusions}

The validation of the PLTEMP/ANLV3.8 code was carried out by comparing the calculation results of the designed LEU core to the experimental data of the HEU core of the DNRR with extremely good consistency. The maximum discrepancy in the fuel cladding temperatures was about $0.8^{\circ} \mathrm{C}$, as shown in Figure 5. This implies that this code can be applied to analyze steady-state thermal-hydraulics for the DNRR's LEU core with annulus fuel VVR-M2 tube-type and natural convection, with an extracting well at the core top.

The designed working core with 92 LEU FBs and 12 beryllium rods was evaluated and subjected to steady-state thermal hydraulic analysis without hot channel factors at the nominal thermal power of $500 \mathrm{~kW}$. The obtained results show that, at the hottest $\mathrm{FB}$, the fuel cladding temperature was only $90.4^{\circ} \mathrm{C}$, as shown in Figure 7, which was far below the limitation of the VVR-M2 fuel cladding temperature of $103^{\circ} \mathrm{C}$, the $\mathrm{ONB}$ temperature was about $115.8^{\circ} \mathrm{C}$, according to the Forster-Greif correlation, the minimum DNBR value was about 32.0, and the minimum ONBR was about 1.43. Thus, the operation condition in this case met all the requirements for thermal-hydraulic safety.

When the systematic uncertainties were taken into account, the maximum fuel cladding temperature was predicted to be $98.4^{\circ} \mathrm{C}$, as shown in Figure 9, which again was well below the limit value of $103^{\circ} \mathrm{C}$. The ONB temperature was about $115.9^{\circ} \mathrm{C}$, the minimum DNBR value was 17.79 , and the minimum ONBR was about 1.26, which was below recommended value of 1.4. However, the coolant temperature at the outlet of the hottest $\mathrm{FB}$ was about $58.8^{\circ} \mathrm{C}$, which was extremely low compared with the saturation temperature of $107^{\circ} \mathrm{C}$. This means that the DNRR still met the thermal hydraulic safety at steady-state condition with application of the global hot channel factors.

When all systematic as well as random uncertainties were applied to a limiting calculation, the maximum fuel cladding temperature obtained was $114.3^{\circ} \mathrm{C}$, which was several degrees below the $\mathrm{ONB}$ point of $116.4^{\circ} \mathrm{C}$. The minimum DNBR value, according to Shah's correlation, was estimated as 15.2, which was much higher than the acceptable criterion of 1.5 , but ONBR value was only 1.02 and obtained near to the boiling point for the DNRR.

From the above results we can conclude that the DNRR core loaded with VVR-M2 LEU FBs is safe at the steady-state condition, from a thermal-hydraulic point of view in cases without hot channel factors and with global hot channel 
factors, and the reactor can be safely operated within the thermal design limit and nominal power of $500 \mathrm{~kW}$, with natural convection adopted for heat removal.

\section{Data Availability}

Data will be made available upon request.

\section{Conflicts of Interest}

The authors declare that they have no conflicts of interest regarding the publication of this paper.

\section{Acknowledgments}

The authors are grateful to the administrative staff of DNRI for their kind support. The staff at Reactor Physics and Engineering Department of DNRI are acknowledged for their valuable technical discussions. Collaboration with the staff of Argonne National Laboratory is greatly appreciated. This research was supported by Ministry of Science and Technology of Vietnam under Grant No. DTCB.10/19/ VNCHN.

\section{References}

[1] N. D. Nguyen, Safety Analysis Report for the Dalat Nuclear Research Reactor, Nuclear Research Institute, Vietnam Atomic Energy Institute, Hanoi, Vietnam, 2009.

[2] N. D. Nguyen, L. B. Vien, V. Le et al., "Results of operation and utilization of the Dalat nuclear research reactor," Nuclear Science and Technology, Vietnam Atomic Energy Association, vol. 4, no. 1, , pp. 1-9, 2014.

[3] G. T. T. Phan, H. N. Tran, K. C. Nguyen et al., "Comparative analysis of the dalat nuclear research reactor with HEU fuel using SRAC and MCNP5," Science and Technology of Nuclear Installations, vol. 2017, Article ID 2615409, 10 pages, 2017.

[4] Q. B. Do, G. T. T. Phan, K.-C. Nguyen, Q. H. Ngo, and H.-N. Tran, "Criticality and rod worth analysis of the DNRR research reactor using the SRAC and MCNP5 codes," Nuclear Engineering and Design, vol. 343, pp. 197-209, 2019.

[5] X-5 Monte Carlo Team, MCNP - A General Monte Carlo N-Particle Transport Code. Version 5. LA-UR-03-1987, Los Alamos National Security LLC, Los Alamos, NM, USA, 2003.

[6] J. G. Stevens, The Rebus-MCNP Linkage, Argonne National Laboratory, Lemont, IL, USA, 2008.

[7] M. B. Chadwick, P. Oblozinsky, M. Herman et al., "ENDF/BVII.0: next generation evaluated nuclear data library for nuclear science and technology," Nuclear Data Sheets, vol. 107, no. 12, pp. 2931-3060, 2006.

[8] A. P. Olson and M. Kalimullah, "A user's guide to the PLTEMP/ANL V3.8 code," ANL/RERTR, Argonne National Laboratory, Lemont, IL, USA, TRN: US1600226, 2009.

[9] N. A. Hanan and P. L. Garner, "Neutronic, steady state and transient analyses for the Kazakhstan WWR-K reactor with LEU fuel. ANL independent verification results," Argonne National Laboratory, Lemont, IL, USA, ANL/RTR/TM-15/7, 120766, 2015.

[10] S. N. Koltochnik and A. A. Shaimerdenov, "Safety analysis for the WWR-K research reactor converted to LEU fuel," Eurasian Journal of Physics and Functional Materials, vol. 3, no. 3, pp. 204-218, 2019.
[11] P. L. Garner and N. K. Hanan, "Transient analyses for the Uzbekistan VVR-SM reactor with IRT-3M HEU fuel and IRT-4M LEU fuel. ANL independent verification results," Argonne National Laboratory, Lemont, IL, USA, TRN: US0803715, 2007.

[12] S. Kadalev, "Thermal hydraulic calculations of the IRT-SOFIA research reactor with LEU Fuel IRT-4M, Sofia," Comptes rendus de l'Academie bulgare des sciences: sciences mathematiques et naturelles, vol. 65, no. 9, pp. 1185-1192, 2012.

[13] N.-D. Nguyen, K.-C. Nguyen, T.-N. Huynh, D.-H. Dang Vo, and H.-N. Tran, "Conceptual design of a $10 \mathrm{MW}$ multipurpose research reactor using VVR-KN fuel," Science and Technology of Nuclear Installations, vol. 2020, Article ID 7972827, 11 pages, 2020.

[14] F. Ameyaw, A. Ayensu, and E. H. K. Akaho, "Modeling and simulation of coupled nuclear heat energy deposition and transfer in the fuel assembly of the Ghana Research Reactor-1 (GHARR-1)," Nuclear Engineering and Design, vol. 241, no. 12 , pp. $5183-5188,2011$.

[15] E. Shitsi, P. Amoah, E. Ampomah-Amoako, and H. C. Odoi, "Steady-state safety analysis of Ghana research reactor-1 with low-enriched-uranium core," Journal of Thermal Science and Engineering Applications, vol. 12, no. 5, pp. 1-18, 2020.

[16] M. Kalimullah, A. P. Olson, E. E. Feldman et al., "Verification and validation of the PLTEMP/ANL code for thermal-hydraulics analysis of experimental and test reactors," Argonne National Laboratory, Lemont, IL, USA, TRN: 161160, 2015.

[17] D. A. Castellanos-Gonzalez, J. M. Losada Moreira, J. Rubens Maiorino, and C. Pedro, "Validation of the cotenp code: a steady-state thermal-hydraulic analysis code for nuclear reactors with plate type fuel assemblies," Science and Technology of Nuclear Installations, vol. 2018, Article ID 9874196, 17 pages, 2018.

[18] VVR-M2 and VVR-M5 Fuel Bundles - Operation Manual”, 0001.04.00.000 РЛ, 2006.

[19] K. Mishima, K. Kanda, and T. Shibata, Thermal-hydraulic Analysis for Core Conversion to the Use of Low-Enrichment Uranium Fuels in KUR, KURRI-TR-258, Research Reactor Institute, Kyoto University, Kyoto, Japan, 1984.

[20] W. L. Woodruff and R. S. Smith, A Users Guide to PARET/ ANL, Version 7.5, Argonne National Laboratory, Lemont, IL, USA, 2006.

[21] H. William, S. A. Teukolsky, W. T. Vetterling, and B. P. Flannery, Numerical Recipes in FORTRAN, the Art of Scientific Computing, Cambridge University Press, Cambridge, England, 2nd edition, 1992.

[22] J. G. Collier and J. R. Thome, Convective Boiling and Condensationp. 185, 3rd edition, Clarendon Press, Oxford, UK, 1994.

[23] M. M. Shah, "Improved general correlation for critical heat flux during upflow in uniformly heated vertical tubes," International Journal of Heat and Fluid Flow, vol. 8, no. 4, pp. 326-335, 1987.

[24] E. E. Feldman, Recommended Treatment of Hot Channel Factors in the PLTEMP Code, Intra-Laboratory Memorandum, Argonne National Laboratory, Lemont, IL, USA, 2006. 